The Geneva Papers on Risk and Insurance, 17 (No. 65, October 1992), 514-529

\title{
Policing the North Sea: The Impact of Fisheries Protection Activity
}

\author{
by Paul Fenn*
}

\section{Introduction}

The common property resource problem which lies at the heart of environmental economics is nowhere more evident than in the commercial exploitation of the sea. Indeed, the 'overfishing' example is the usual textbook approach to this problem, where the absence of well-defined property rights over international waters leads to each individual vessel increasing its catch up to the point at which the cost per vessel equals the marginal revenue from the catch. The marginal social cost of increasing the size of each catch is ignored, with the consequence that fishstocks become exhausted.

The obvious regulatory response to this problem is for international cooperation in enforcing limitations on fishing activity, particularly where there is evidence of fishstock depletion. With respect to the North Sea, one of the most heavily fished seas in the world, the relevant standards are based on scientific advice from the International Council for the Exploration of the Sea (ICES). This advice is passed on to the North East Atlantic Fisheries Commission, who are responsible for defining strict rules governing the areas which can be fished, agreed quotas for particular species, and allowable net sizes. These are then incorporated into both national and $\mathrm{EC}$ law, with responsibilities for enforcement devolving to individual member states. This paper is concerned with the enforcement regime set up by the UK, namely the Sea Fisheries Inspectorates at the Ministry of Agriculture Fisheries and Food (MAFF) and the Department of Agriculture and Fisheries for Scotland (DAFS).

The topicality of this particular environmental issue is evident. The European Commission is proposing a radical overhaul of the common fisheries policy with effect from 1992, in response particularly to a dramatic decline in the known stocks of cod and haddock in the North Sea. Four successive years of cuts in the catch quotas for these two species

* Centre for Socio-Legal Studies, Oxford University.

This paper was presented at a Conference on the Law and Economics of Environmental Policy organized by the European Association of Law and Economics in conjunction with the Geneva Association, Paris April 4-5, 1991. I am grateful to the participants at that conference, in particular Lewis Kornhauser and Michael Faure, for helpful comments. I am also grateful to Eric Larnegan for research assistance, and to officials of the Fisheries Laboratory and the Fisheries Statistics Unit of MAFF for providing data. Two anonymous referees of this journal also provided helpful comments. 
allocated to EC member states have failed to prevent stocks falling to levels "that scientists fear might put them beyond recovery unless further action is taken". ${ }^{1}$ The European Fisheries Commissioner has argued that catch quotas have not worked, and has proposed to increase the permissible mesh size from $90 \mathrm{~mm}$ to $120 \mathrm{~mm}$, in order to allow immature fish to escape. In the meantime, surveillance of vessels should be improved, using a combination of satellite tracking technology and a computerised vessel location network. The Commissioner maintains that some EC countries are "abusing quotas, not policing their fishing fleets, not monitoring catches and nets used, and not stopping the building of boats". ${ }^{2}$ While it is acknowledged that current overcapacity in the fishing industry may be up to $40 \%$, the British government favours traditional enforcement methods for reducing fishing activity rather than the extensive use of decommissioning grants. The research reported in this paper arose out of work commissioned by the National Audit Office (NAO) in relation to their examination of the extent and nature of public support to the sea-fishing industry (NAO, 1987).

The paper begins by examining the statistical relationship between observed fishstocks and aggregate catches, with a view to demonstrating the logic of conservation. The paper then proceeds by summarizing from an earlier paper a model of the enforcement activity of a public interest-maximizing regulatory agency faced with exogenous standards. It is argued that such an agency would target its activity in order to maximize its effectiveness. As a result any attempt to estimate the effect of fishery protection activity on compliance with agreed national quotas must model both the targetting decision of the agency and the compliance decision of the regulated fishing fleets. The following section discusses the nature of the data on enforcement and compliance, as obtained on a monthly basis for two species (cod and haddock), and for six countries (Belgium, Denmark, France, Germany, Netherlands, UK). The next section introduces issues of methodology: in addition to the potential simultaneity bias, there was also the possibility of heteroskedasticity due to a variation in the reliability of the data between different countries and across different timeperiods. A combination of a distributed lag formulation together with White's correction for unknown heteroskedasticity is therefore proposed to obtain consistent estimates of the parameters. Finally, the results are reported, and are used in the conclusion to make recommendations in relation to the desirable linkages between enforcement policy and observed quota take-up and fishstock. ${ }^{3}$

\section{Modelling fishstocks}

Clearly, the successful management of North Sea fishery resources depends on the capacity of existing species to reproduce in large enough numbers to maintain a stock sufficient to satisfy the demands of the market. For this reason, the monitoring of the size and age breakdown of fishstocks is undertaken by the International Council for the Exploration of the Sea (ICES) with a view to assessing catch options inside safe biological limits for each species. The ICES Advisory Committee on Fishery Management recommends catch quotas

1 The Times, November 20, 1990, p. 6.

2 The Times, November 29, 1990, p. 14.

${ }^{3}$ There is of course a wide literature on the economics of fisheries and fisheries law enforcement, which this paper does not attempt to review. The objective here is to illustrate some of the conservation and enforcement issues from a law and economics perspective. 
by area based on forecasts for fishstocks under various assumptions about fishing activity. It is then up to the EC to determine how to divide up the quotas between member states.

The statistical modelling process involved in producing these stock assessments is undertaken by ICES Working Groups using survey data collected by member states. These data allow an age breakdown of current stocks, which in turn permits calculation of the survival rate of spawn together with the stock of fish of spawning age. Haddock spawns once a year when 3 years old and over, cod when 4 years old and over. Without fishing, changes in the spawning stock of each species would be determined by the numbers of surviving spawn ('recruitment') together with natural mortality in other years. With fishing, mortality is increased to an extent determined by the yield for human consumption and industrial byproducts, as well as the mortality rate amongst those fish discarded as being too small for the market. The forecasts of future spawning stock levels are therefore based on alternative assumptions about overall mortality from fishing, using a technique known as virtual population analysis. In essence, it is possible to model the relationship between fishing activity in the current period, and the level of the 'spawning stock biomass' (SSB) in the following period, given age-specific population data from surveys. Figure 1 shows the variations over time in aggregate landings, SSB and recruitment for haddock in the North Sea.

Figure 1:

Landings, spawning stock and recruitment North Sea Haddock

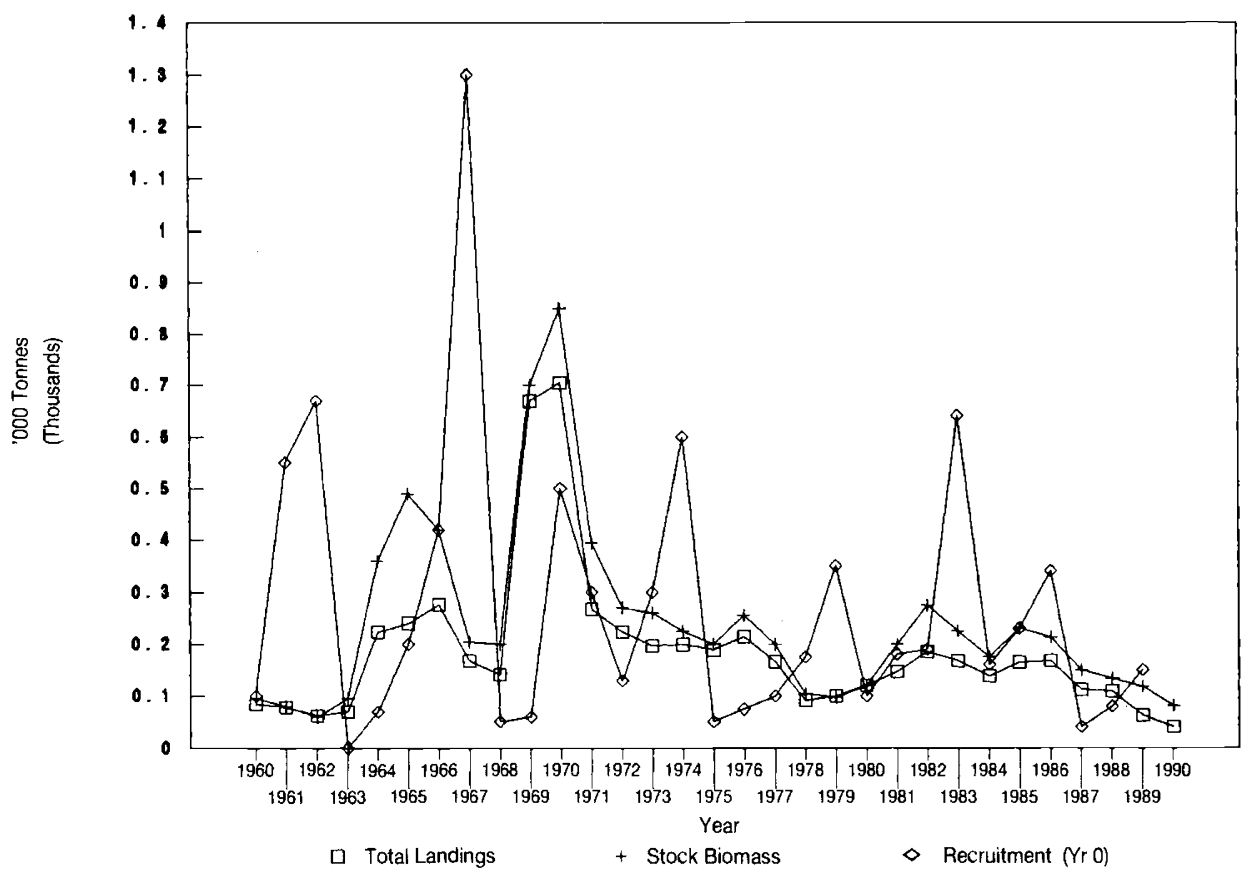


In a simplified form, the relationship between aggregate catches and SSB can be represented as follows:

$$
\begin{aligned}
c_{t} & =f\left(S_{t}, e_{t}\right) \\
S_{t} & =g\left(S_{t-l}, r_{t-3}, c_{t-l}, c_{t-2}\right) \\
\text { where } & c_{t}=\text { aggregate catch, year } t \\
S_{t} & =\text { spawning stock biomass, year } t \\
e_{t} & =\text { fishing effort, year } t \\
r_{t} & =\text { recruitment, year } t .
\end{aligned}
$$

\begin{tabular}{|c|c|c|c|}
\hline \multicolumn{3}{|c|}{ MEAN OF DEPENDENT VARIABLE $=$} & 216.000 \\
\hline \multicolumn{3}{|c|}{ R-SQUARED $=$} & 0.379929 \\
\hline \multicolumn{3}{|c|}{ ADJUSTED R-SQUARED $=$} & 0.352969 \\
\hline \multicolumn{3}{|c|}{ DURBIN-WATSON STATISTIC $=$} & 0.9495 \\
\hline & F-STATISTIC ( & $1, \quad 23)=$ & 14.0925 \\
\hline \multicolumn{3}{|c|}{ LOG OF LIKELIHOOD FUNCTION $=$} & -130.833 \\
\hline \multicolumn{3}{|c|}{ NUMBER OF OBSERVATIONS = } & 25 \\
\hline & ESTIMATED & STANDARD & \\
\hline VARIABLE & COEFFICIENT & ERROR & T-STATISTIC \\
\hline C & 109.29 & 29.957 & 3.6483 \\
\hline CMASS & 0.65417 & 0.17426 & 3.7540 \\
\hline
\end{tabular}

Table 1:

Modelling fishstocks for cod ${ }^{4}$

\begin{tabular}{|c|c|c|c|}
\hline \multicolumn{3}{|c|}{ MEAN OF DEPENDENT VARIABLE $=$} & 163.120 \\
\hline \multicolumn{3}{|c|}{ ADJUSTED R-SQUARED = } & 0.887312 \\
\hline \multicolumn{3}{|c|}{ DURBIN-WATSON STATISTIC = } & 1.3076 \\
\hline & F-STATISTIC ( & $4, \quad 20)=$ & 48.2444 \\
\hline \multicolumn{3}{|c|}{ LOG OF LIKELIHOOD FUNCTION $=$} & -105.751 \\
\hline \multicolumn{3}{|c|}{ NUMBER OF OBSERVATIONS = } & 25 \\
\hline & ESTIMATED & STANDARD & \\
\hline VARIABLE & COEFFICIENT & ERROR & T-STATISTIC \\
\hline $\mathrm{C}$ & 9.7603 & 21.134 & 0.46182 \\
\hline CMASSL & 1.0280 & 0.10065 & 10.214 \\
\hline CCATCHL1 & $-0.93494 \mathrm{E}-01$ & 0.11206 & -0.83434 \\
\hline CCATCHL2 & $0.23314 \mathrm{E}-01$ & $0.92221 \mathrm{E}-01$ & 0.25280 \\
\hline RECRL3 & $-0.13264 \mathrm{E}-01$ & $0.29692 \mathrm{E}-01$ & -0.44672 \\
\hline
\end{tabular}

EQUATION 1

DEPENDENT VARIABLE: CCATCH

EQUATION 2

DEPENDENT VARIABLE: CMASS

\footnotetext{
${ }^{4}$ See Appendix for list of variable mnemonics.
} 
Table 2:

Modelling fishstocks for haddock ${ }^{5}$

EQUATION 1

DEPENDENT VARIABLE: HCATCH

\begin{tabular}{|c|c|c|c|}
\hline $\mathrm{ME}$ & AN OF DEPENDEN & /ARIABLE = & 198.321 \\
\hline & & SQUARED $=$ & 0.917700 \\
\hline & ADJUSTED & SQUARED = & 0.914535 \\
\hline & DURBIN-WATSO & STATISTIC $=$ & 1.2326 \\
\hline & F-STATISTIC ( & 1, 26) $=$ & 289.919 \\
\hline & OG OF LIKELIHOOI & GUNCTION = & -144.614 \\
\hline & NUMBER OF OBS & RVATIONS = & 28 \\
\hline & ESTIMATED & STANDARD & \\
\hline VARIABLE & COEFFICIENT & ERROR & T-STATISTIC \\
\hline C & -10.995 & 14.835 & -0.74116 \\
\hline HMASS & 0.80851 & $0.47484 \mathrm{E}-01$ & 17.027 \\
\hline
\end{tabular}

EQUATION 2

DEPENDENT VARIABLE: HMASS

\begin{tabular}{|c|c|c|c|}
\hline \multicolumn{3}{|c|}{ MEAN OF DEPENDENT VARIABLE = } & 258.893 \\
\hline \multicolumn{3}{|c|}{ R-SQUARED $=$} & 0.669119 \\
\hline \multicolumn{3}{|c|}{ ADJUSTED R-SQUARED $=$} & 0.611575 \\
\hline \multicolumn{3}{|c|}{ DURBIN-WATSON STATISTIC $=$} & 1.7835 \\
\hline & F-STATISTIC ( & 4, $\quad 23)=$ & 11.6279 \\
\hline \multicolumn{3}{|c|}{ LOG OF LIKELIHOOD FUNCTION $=$} & -168.843 \\
\hline \multicolumn{3}{|c|}{ NUMBER OF OBSERVATIONS = } & 28 \\
\hline & ESTIMATED & STANDARD & \\
\hline VARIABLE & COEFFICIENT & ERROR & T-STATISTIC \\
\hline $\mathrm{C}$ & 38.059 & 49.669 & 0.76626 \\
\hline HMASSL & 1.0048 & 0.44522 & 2.2568 \\
\hline HCATCHL1 & -0.62710 & 0.56158 & -1.1167 \\
\hline HCATCHL2 & $-0.87463 \mathrm{E}-01$ & 0.22275 & -0.39264 \\
\hline RECRL3 & 0.36877 & 0.10755 & 3.4288 \\
\hline
\end{tabular}

${ }^{5}$ See Appendix for a list of variable mnemonics. 
The first function shows the evident dependence of marketable yield on the available stock of mature fish, for any given amount of fishing activity. The second function shows the way in which current fishstocks are dependent on previous survival and mortality rates. Tables 1 and 2 show the OLS regression results of estimating these two equations for cod and haddock respectively using catch, SSB, and recruitment data from 1960-1990. Fishing effort is a rather difficult variable to measure consistently, and therefore it is treated here as an unobservable, although the ICES model itself does incorporate survey data on fishing effort.

These results reveal both that fishing yields are highly sensitive to the size of the SSB, and that previous fishing activity affects current stocks (although the evidence for this is rather more tentative). It is underlying relationships of this kind which demonstrate both the need for, and the limitations of, fishery protection activity.

\section{Modelling fishery protection activity}

After taking account of the ICES stock assessment calculations, and associated recommendations, the EC sets 'Total Allowable Catches' (TACs) for each species and area. These TACs are then allocated between member states in the form of national quotas on the basis of agreed criteria. These may be revised subsequently as the result of "quota swaps'. Each member state is then legally responsible for the enforcement of EC regulations within its waters.

British government fisheries protection activities in the North Sea are the joint responsibility of the Ministry of Agriculture Fisheries and Food (MAFF), and the Department of Agriculture and Fisheries for Scotland (DAFS). These bodies are responsible for surveillance and control of fishing activities within the British fishing limits. Control measures include quota limitations on the species, size, and quantity of fish to be caught in different control areas, and restrictions on mesh sizes in nets, and on who may fish.

The UK quota allocations for each species must first be divided up amongst the fishing fleets. This is achieved by means of a two stage process. First, the major producer organizations are invited to apply annually for 'sectoral quotas', and these are allocated in relation to their historic catch as estimated from landing declarations. The remaining, 'non-sectoral', part of the national quota is allocated monthly by negotiation between representatives of the fishing industry and government, and this process leads to monthly catch restrictions by category of vessel.

The effective enforcement of sectoral and non-sectoral allocations consequently depends on the monitoring of both landings and fishing activity at sea. Control is exercised using aerial surveillance, inspection and enforcement at sea, as well as the land-based inspections of the Sea Fisheries Inspectorates at the main fishing ports. The main objective of aerial surveillance is to establish patterns of fishing, thereby enabling the fleet of surface fishery protection vessels to be deployed more effectively. These vessels are operated by the Royal Navy as well as DAFS, and the principal means of enforcement is through the boarding and subsequent inspection of fishing vessels suspected of non-compliance with the limitations listed above. Clearly, the definition of compliance will depend upon whether the vessel concerned is governed by sectoral or non-sectoral rules of allocation. In the latter case, overfishing can be detected in relation to the monthly catch limits for each vessel. In the former, the fleet is essentially self-regulatory with respect to the aggregate catch, and compliance will therefore relate only to the manner in which the catch is made. In a relati- 
vely rare number of cases further action may be taken following a boarding, and only exceptionally will this lead to a prosecution. This pattern of enforcement activity, in which emphasis is placed upon negotiated compliance with cooperative offenders, is typical of enforcement agencies in the UK which are faced with achieving compliance with externally determined standards given a fixed budget.

Consequently, the model of enforcement and compliance activity to be estimated here is adapted from one which I have developed previously in relation to the enforcement of health and safety regulations (Fenn, 1987; Fenn and Veljanovski, 1987). It was argued there that previous attempts at the estimation of regulatory impact had tended to ignore the enforcement process itself. A complete model needs to take account of the layers of discretion in the enforcement process: discretion over the frequency of inspection, over the definition of compliance, and over the degree of formality in enforcement. This approach necessitates a simultaneous equation model similar to those used in other studies of regulatory impact (Bartel and Thomas, 1982; Viscusi, 1979; Cooke and Gautschi, 1981). In essence, this is because a harm minimizing agency will target its inspections on those offenders who are thought most likely to be avoiding compliance. This means that the most frequent offenders may well be the most frequently inspected: hence a single equation model could produce the perverse effect of a positive correlation between inspection and offending. In an orthodox model of deterrence this would be problematic, as the mechanism for deterring offenders is the expected penalty, which is likely to depend on the frequency of inspection. In a negotiated compliance model of enforcement, it is even more problematic, as the inspection itself is a vehicle for negotiation and the monitoring of cooperation.

Computer readable data on surveillance and enforcement activity is available from the Sea Fisheries Inspectorate at MAFF. A separate database is also available from DAFS. Together, these datasets enable the estimation of fishing activity - the number of sightings and vessels - by nation and area, as well as indicators of enforcement activity - boardings, actions, and prosecutions. Data on landings, total allowable catches, national quota and fish stocks can be obtained from various ICES publications. For the purpose of this study, data were obtained on a monthly basis from 1982 to 1985 inclusive for two species, (cod and haddock) and for six countries (Belgium, Denmark, France, Germany, Netherlands and the UK). Figures 2 and 3 show how fishing and enforcement activity varied over time and between countries during this period.

Given these data, it is possible in principle to estimate the following three-equation model for each species:

$$
\begin{aligned}
& c_{t} / q_{t}=f\left(v_{t}, S_{t}, b_{t} / v_{t}, a_{t} / v_{t}\right) \\
& b_{t} / v_{t}=g\left(c_{t} / q_{t}\right) \\
& a_{t} / v_{t}=h\left(c_{t} / q_{t}, b_{t} / v_{t}\right)
\end{aligned}
$$

where $c_{t}$ and $S_{t}$ are as before, and

$q_{t}=$ quota in period $t$

$v_{t}=$ vessels in period $t$

$b_{t}=$ boardings in period $t$

$a_{t}=$ actions taken after boardings in period $t$.

Equation 3 is a compliance equation, with a view to explaining variations in quota takeup across countries and over time. As above, it is assumed that catches are determined by the available fishstocks as well as fishing effort (proxied here by the number of vessels). 
Figure 2:

Sightings in North Sea by country

Seasonally adjusted

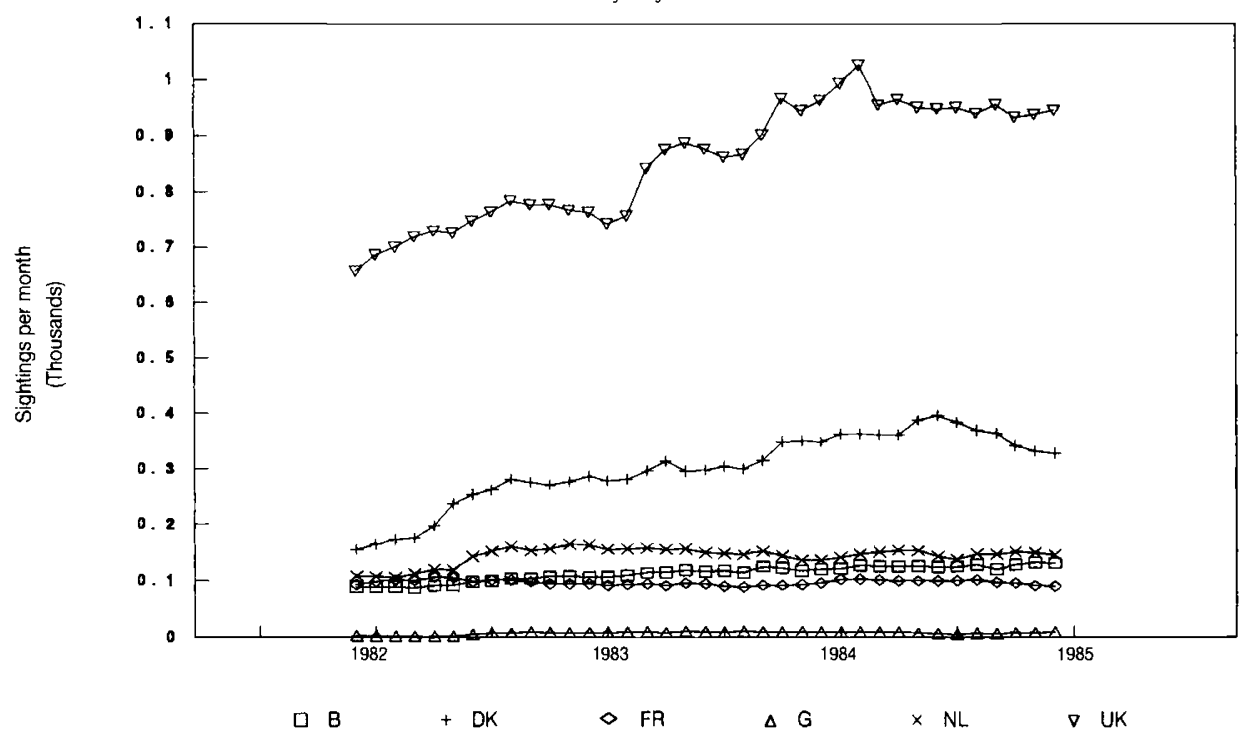

Figure 3:

Boardings in North Sea by country

Seasonally adjusted

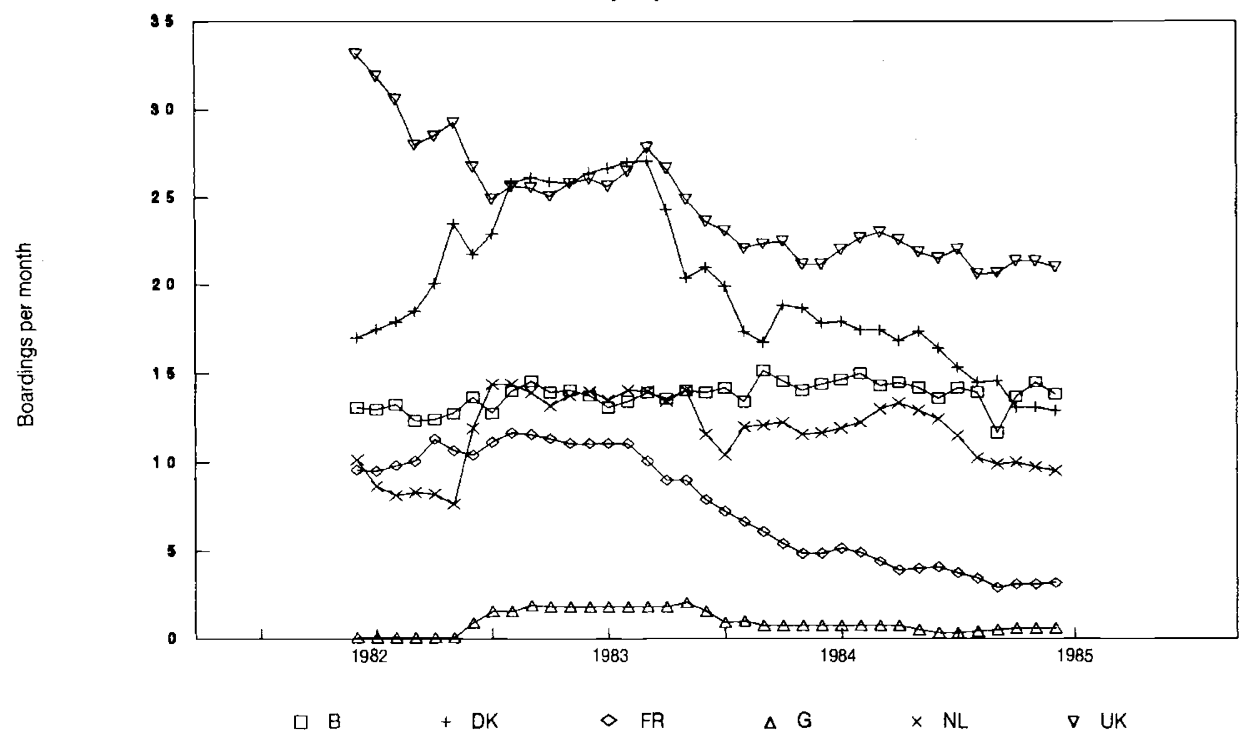


In addition, the degree to which quotas are taken up or exceeded will depend on enforcement activity, as measured by boardings and subsequent actions. Equations 4 and 5 reflect the possibility that enforcement activity will be targetted in relation to observed variations in quota takeup. Clearly, in the form represented above, this model would not be identified as a result of the endogeneity of enforcement activity and insufficient identifying restrictions. However, there are sound reasons to believe that both the targetting decisions of the SFI and the compliance decisions of the fishing fleets operate subject to significant lags. Consequently the availability of monthly data permits us to incorporate a geometric distributed lag structure into all three equations and thereby avoid simultaneity problems. These can then be conveniently converted into autoregressive forms:

$$
\begin{aligned}
& c_{t} / q_{t}=f\left(c_{t-1} / v_{t-1}, v_{t}, S_{t}, b_{t-1} / v_{t-1}, a_{t-1} / v_{t-1}\right) \\
& b_{t} / v_{t}=g\left(b_{t-1} / v_{t-1}, c_{t-1} / q_{t-1}\right) \\
& a_{t} / v_{t}=h\left(a_{t-1} / v_{t-1}, c_{t-1} / q_{t-1}, b_{t} / v_{t}\right)
\end{aligned}
$$

The stochastic versions of these equations can then be estimated consistently by OLS, providing that the error terms are not significantly serially correlated.

A further problem which arises in estimating the above model is that of heteroskedasticity. As we have seen, use is made of pooled cross-section and time-series data, with the intercept only assumed to vary across countries. Hence the empirical equation estimates are of the general form:

$$
y_{i}=\left(\beta_{1}+\mu_{i}\right) j_{T}+X_{s i} \beta_{s}+e_{i}
$$

where for each country $(i=1, \ldots 6), y_{i}$ and $e_{i}$ are vectors of dimension 48 (the number of months), $j_{T}$ is a unit vector, and $X_{s i}$ contains values of the explanatory variables except for the constant. If it could be assumed that $E\left[e_{i} e_{i}{ }^{\prime}\right]=\sigma_{e}^{2} I_{T}$, then ordinary least squares estimation would be best linear unbiased. However, there is good reason to believe that the errors will be heteroskedastic in this model, given that the data is derived from the activity of six different national fishing fleets in UK waters. Unfortunately, there was no real means of discovering the precise Generalised Least Squares estimates. Therefore it was necessary to adopt a technique which computes consistent standard errors in the presence of unknown heteroskedasticity by using the data to estimate its magnitude (see White, 1980, 1982; Chamberlain, 1984). This technique was used in conjunction with OLS in order to estimate the equation parameters.

\section{Results}

\subsection{Compliance equations}

Table 3 and 4 give the results for the compliance equations for each species. These represent an attempt to explain the variations in quota take up between countries and over time, with a view to capturing the nature of the relationship between quota take up and enforcement activity: the latter is represented by boardings per vessel and actions per vessel. However, there are other things which might arguably affect the fish catch in relation to quota:

i) some countries may be more likely to take up or exceed quotas;

ii) there may be a seasonal pattern to the catch;

iii) more vessels in the British zone may imply more vessels in the quota area overall and hence increased overall fishing effort;

iv) as we have shown above, catches will presumably be higher in years when the fish stock is high (however, one might expect quotas also to be higher: so the overall effect on quota takeup may be neutral). 
Table 3:

Modelling compliance for cod 6

DEPENDENT VARIABLE: CODTAKE

\begin{tabular}{|c|c|c|c|}
\hline \multicolumn{3}{|c|}{ MEAN OF DEPENDENT VARIABLE = } & 0.880501 \\
\hline & \multicolumn{2}{|c|}{ R-SQUARED $=$} & 0.274163 \\
\hline & \multicolumn{2}{|c|}{ ADJUSTED R-SQUARED = } & 0.215538 \\
\hline DURBIN-WATS & & 1.9745 \\
\hline & \multicolumn{2}{|c|}{$\begin{aligned} & \text { SON STATISTIC (ADJ. FOR } 5 \text { GAPS) }= \\
& \text { F-STATISTIC }\left(\begin{array}{rl}21, & 260)\end{array}=\right.\end{aligned}$} & 4.67653 \\
\hline & \multicolumn{2}{|c|}{ LOG OF LIKELIHOOD FUNCTION $=$} & -175.926 \\
\hline & \multicolumn{2}{|c|}{ NUMBER OF OBSERVATIONS = } & 282 \\
\hline & ESTIMATED & STANDARD & \\
\hline VARIABLE & COEFFICIENT & ERROR & T-STATISTIC \\
\hline $\mathrm{C}$ & $-0.16547 \mathrm{E}-02$ & 0.19138 & $-0.86464 \mathrm{E}-02$ \\
\hline DUMDEN & $0.95508 \mathrm{E}-01$ & $0.88810 \mathrm{E}-01$ & 1.0754 \\
\hline DUMFRA & $0.54088 \mathrm{E}-01$ & $0.88926 \mathrm{E}-01$ & 0.60823 \\
\hline DUMGER & -0.19828 & $0.87449 \mathrm{E}-01$ & -2.2674 \\
\hline DUMNET & 0.15695 & $0.98737 \mathrm{E}-01$ & 1.5895 \\
\hline DUMUK & -0.20886 & 0.12642 & -1.6521 \\
\hline FEB & 0.42382 & 0.16151 & 2.6241 \\
\hline MAR & 0.35126 & 0.15004 & 2.3411 \\
\hline APR & $0.42941 \mathrm{E}-01$ & 0.11558 & 0.37151 \\
\hline MAY & 0.21164 & 0.12915 & 1.6386 \\
\hline JUN & 0.28266 & 0.11531 & 2.4512 \\
\hline JUL & 0.17495 & 0.12232 & 1.4302 \\
\hline AUG & $0.90916 \mathrm{E}-01$ & 0.12656 & 0.71835 \\
\hline SEP & 0.24223 & 0.12439 & 1.9474 \\
\hline OCT & $0.62669 \mathrm{E}-01$ & 0.13968 & 0.44865 \\
\hline NOV & 0.29212 & 0.15321 & 1.9066 \\
\hline DEC & 0.48731 & 0.16260 & 2.9969 \\
\hline VESSELS & $0.10427 \mathrm{E}-02$ & $0.38766 \mathrm{E}-03$ & 2.6897 \\
\hline CMASS & $0.64606 \mathrm{E}-03$ & $0.21103 \mathrm{E}-03$ & 3.0615 \\
\hline CODTAKEL & 0.24737 & $0.89862 \mathrm{E}-01$ & 2.7528 \\
\hline BOARDVL & $-0.87240 \mathrm{E}-01$ & $0.93075 \mathrm{E}-01$ & -0.93731 \\
\hline ACTVL & -0.68207 & 1.2068 & -0.56519 \\
\hline
\end{tabular}

S.E.S. and variance shown are heteroskedastic-consistent estimates.

${ }^{6}$ See Appendix for a list of variable mnemonics. 
Table 4:

Modelling compliance for haddock ${ }^{7}$

DEPENDENT VARIABLE: HADTAKE

\begin{tabular}{|c|c|c|c|}
\hline & MEAN OF DEPENDEN & ARIABLE = & 0.952180 \\
\hline & & SQUARED = & 0.322304 \\
\hline & ADJUSTED & SQUARED = & 0.267567 \\
\hline DURBIN-WATS & ON STATISTIC (ADJ. & R 5 GAPS) $=$ & 2.0093 \\
\hline & F-STATISTIC ( & , 260) $=$ & 5.88823 \\
\hline & LOG OF LIKELIHOOI & UNCTION = & -347.172 \\
\hline & NUMBER OF OBS & RVATIONS = & 282 \\
\hline & ESTIMATED & STANDARD & \\
\hline VARIABLE & COEFFICIENT & ERROR & T-STATISTIC \\
\hline $\mathrm{C}$ & -0.29145 & 0.22165 & -1.3149 \\
\hline DUMDEN & 0.57134 & 0.15666 & 3.6471 \\
\hline DUMFRA & 0.16942 & 0.12564 & 1.3484 \\
\hline DUMGER & $-0.77755 \mathrm{E}-01$ & $0.81151 \mathrm{E}-01$ & -0.95815 \\
\hline DUMNET & 0.57280 & 0.24336 & 2.3538 \\
\hline DUMUK & 0.38549 & 0.17372 & 2.2191 \\
\hline FEB & 0.32347 & 0.13310 & 2.4302 \\
\hline MAR & 0.49976 & 0.15621 & 3.1993 \\
\hline APR & 0.31476 & 0.10769 & 2.9227 \\
\hline MAY & 0.34317 & 0.11025 & 3.1127 \\
\hline JUN & 0.71544 & 0.15462 & 4.6271 \\
\hline JUL & 0.93641 & 0.21780 & 4.2995 \\
\hline AUG & 1.6267 & 0.41477 & 3.9221 \\
\hline SEP & 1.1089 & 0.21118 & 5.2511 \\
\hline OCT & 0.90287 & 0.14802 & 6.0996 \\
\hline NOV & 0.27935 & 0.12162 & 2.2969 \\
\hline DEC & 0.40755 & 0.13109 & 3.1088 \\
\hline VESSELS & $-0.24266 \mathrm{E}-03$ & $0.59277 \mathrm{E}-03$ & -0.40937 \\
\hline HMASS & $0.19269 \mathrm{E}-03$ & $0.15698 \mathrm{E}-03$ & 1.2275 \\
\hline HADTAKEL & 0.14552 & $0.66311 \mathrm{E}-01$ & 2.1944 \\
\hline BOARDVL & -0.10455 & 0.16485 & -0.63421 \\
\hline ACTVL & 5.0944 & 2.4289 & 2.0974 \\
\hline
\end{tabular}

S.E.S. and variance shown are heteroskedastic-consistent estimates.

${ }^{7}$ See Appendix for a list of variable mnemonics. 
Table 5:

Modelling boardings per vessel ${ }^{8}$

DEPENDENT VARIABLE: BOARDVES

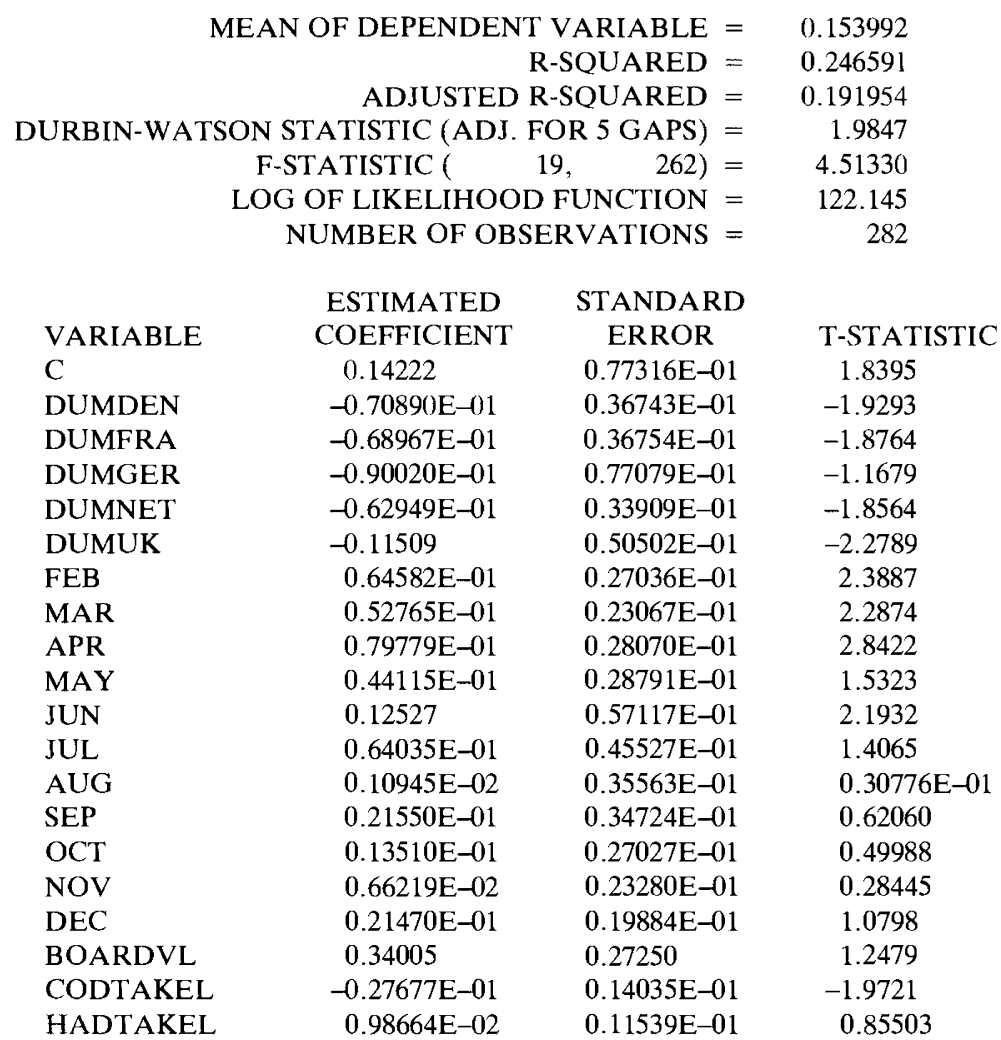

S.E.S. and variance shown are heteroskedastic-consistent estimates.

${ }^{8}$ See Appendix for a list of variable mnemonics. 
Table 6:

Modelling actions per vessel ${ }^{9}$

DEPENDENT VARIABLE: ACTVES

\begin{tabular}{|c|c|c|c|}
\hline & MEAN OF DEPENDEN & ARIABLE $=$ & $0.472903 \mathrm{E}-02$ \\
\hline & & SQUARED = & $0.964108 \mathrm{E}-01$ \\
\hline & ADJUSTED & SQUARED = & $0.271702 \mathrm{E}-01$ \\
\hline URBIN-WATS & SON STATISTIC (ADJ. & R 5 GAPS) $=$ & 1.9655 \\
\hline & F-STATISTIC ( & , 261) $=$ & 1.39240 \\
\hline & LOG OF LIKELIHOO & UNCTION = & 775.291 \\
\hline & NUMBER OF OBS & RVATIONS $=$ & 282 \\
\hline & ESTIMATED & STANDARD & \\
\hline VARIABLE & COEFFICIENT & ERROR & T-STATISTI \\
\hline $\mathrm{C}$ & $0.84221 \mathrm{E}-02$ & $0.34886 \mathrm{E}-02$ & 2.4142 \\
\hline DUMDEN & $0.61222 \mathrm{E}-02$ & $0.25256 \mathrm{E}-02$ & 2.4241 \\
\hline DUMFRA & $0.16079 \mathrm{E}-02$ & $0.21490 \mathrm{E}-02$ & 0.74818 \\
\hline DUMGER & $0.52883 \mathrm{E}-03$ & $0.49531 \mathrm{E}-02$ & 0.10677 \\
\hline DUMNET & $-0.25203 \mathrm{E}-03$ & $0.19830 \mathrm{E}-02$ & -0.12709 \\
\hline DUMUK & $-0.83033 \mathrm{E}-03$ & $0.17137 \mathrm{E}-02$ & -0.48453 \\
\hline FEB & $0.23722 \mathrm{E}-02$ & $0.44589 \mathrm{E}-02$ & 0.53202 \\
\hline MAR & $-0.16522 \mathrm{E}-02$ & $0.35927 \mathrm{E}-02$ & -0.45987 \\
\hline APR & $-0.73617 \mathrm{E}-02$ & $0.26305 \mathrm{E}-02$ & -2.7986 \\
\hline MAY & $-0.73870 \mathrm{E}-02$ & $0.28846 \mathrm{E}-02$ & -2.5608 \\
\hline JUN & $-0.66064 \mathrm{E}-02$ & $0.30931 \mathrm{E}-01$ & -2.1358 \\
\hline JUL & $-0.69314 \mathrm{E}-02$ & $0.26896 \mathrm{E}-02$ & -2.5771 \\
\hline AUG & $-0.63615 \mathrm{E}-02$ & $0.28184 \mathrm{E}-02$ & -2.2571 \\
\hline SEP & $0.45203 \mathrm{E}-02$ & $0.95860 \mathrm{E}-02$ & 0.47155 \\
\hline OCT & $-0.66941 E-02$ & $0.27307 \mathrm{E}-02$ & -2.4514 \\
\hline NOV & $-0.22760 \mathrm{E}-02$ & $0.35009 \mathrm{E}-02$ & -0.65012 \\
\hline DEC & $-0.85919 E-02$ & $0.26116 \mathrm{E}-02$ & -3.2899 \\
\hline BOARDVES & $0.54969 \mathrm{E}-02$ & $0.48898 \mathrm{E}-02$ & 1.1242 \\
\hline ACTVL & $0.41627 \mathrm{E}-01$ & $0.53493 \mathrm{E}-01$ & 0.77817 \\
\hline CODTAKEL & $-0.22227 \mathrm{E}-02$ & $0.13655 \mathrm{E}-02$ & -1.6278 \\
\hline HADTAKEL & $0.45800 \mathrm{E}-04$ & $0.91501 \mathrm{E}-03$ & $0.50054 \mathrm{E}-\mathrm{C}$ \\
\hline
\end{tabular}

S.E.S. and variance shown are heteroskedastic-consistent estimates.

${ }^{9}$ See Appendix for a list of variable mnemonics. 
In addition, we expect that any deterrent effect of enforcement activity by FPV's might be spread over a number of periods. The equations in Table 3 allow for this by using the autoregressive forms implied by geometric distributed lag structures.

The results for cod show that:

i) Germany and the UK are less likely to takeup their quota, the Netherlands possibly more ;

ii) there is no clear seasonal pattern to the catch, apart from January (the control month) being lower than most months;

iii) the number of vessels in British waters and the estimated stock biomass of cod both increase the quota takeup;

iv) the number of boardings per vessel and the number of actions per vessel have a negative effect on quota takeup, but these are not significant at the $10 \%$ level ;

v) lagged quota takeup is significant, confirming the autoregressive structure.

The results for haddock indicate that:

i) Denmark, the UK and the Netherlands are more likely to exceed quota, Germany less;

ii) there is a pronounced seasonal pattern to fishing yields, peaking in late summer/ autumn (i.e. from July to October);

iii) the estimated stock biomass of haddock is a positive, but insignificant factor explaining quota takeup;

iv) boardings per vessel is again a negative but insignificant factor in determining quotatakeup; actions per vessel show a counterintuitive positive and significant effect on takeup;

v) again, lagged quota takeup is significant.

\subsection{Enforcement equations}

The results reported in Tables 5 and 6 are an attempt to explain the variation in enforcement activity in relation to observed fishing activity between countries and over time. Hence the dependent variables are boardings/vessel and actions/vessel respectively. Again, enforcement activity may also be affected by seasonal and national variations, so these are allowed for. Because the targetting policy of FPV's might be influenced by information received only after a lag, an autoregressive lag structure was also built into these specifications.

The results indicate that:

i) there does not appear to be any clear seasonal pattern to enforcement activity;

ii) Belgian vessels are more likely to be boarded than other countries' vessels, and UK vessels are less likely to be boarded; by contrast, Danish vessels are most likely to have action taken against them following a boarding;

iii) there is no indication of a positive targetting policy directing enforcement resources where and when quota takeup is high; indeed, it appears that a high takeup of quotas for cod is followed by less enforcement activity.

\section{Conclusions}

The fundamental rationale for the statutory regulation of fishing activity is based on the notion that the sea is a common property resource, the exploitation of which will result in a 'tragedy of the commons' in the form of a depletion in fishstocks beyond that which is socially optimal. Consequently, it is slightly surprising to find in this study that the relation- 
ship between current fishstocks and previous total landings is quite weak. However, it must be emphasised that the limited exercise undertaken here is only a very rough approximation to the virtual population analysis and associated simulations undertaken by ICES statisticians. The latter have access to catch-by-age survey data which permits a more precise estimation of overall fishing mortality. The relatively poor explanatory power of landings data may be due to the fact that these data do not include information about the level of discards, and the effect that these have on fishing mortality by age. If this factor is important, as seems likely, then it would appear that the EC Fisheries Commissioner is justified in recommending an increase in the mesh size as an alternative means of securing an effective reduction in fishing mortality.

Even if a restriction on total landings was demonstrated to be an effective way of increasing fishstocks, it would need to be shown that such a restriction was capable of being adequately enforced by the relevant agencies. The evidence examined here with respect to sea-based enforcement activity in the North Sea appears to show little effect of boardings and subsequent actions on the reported takeup of national quotas, and hence on the probability that such quotas will be exceeded. Of course, this may again be due to data inadequacy: the critical factor influencing catch decisions - particularly for the sectoral organizations - may be the land-based inspections of the SFIs in monitoring landings, for which we have no information. Because of this, and in view of the discussion in the previous paragraph, it is also possible that the real impact of sea-based enforcement is on the provisions relating to the nature of the catch - the kind of species, the age breakdown of the catch, the mesh size etc. ${ }^{10}$

In the wider context, are there any alternative mechanisms for controlling the overfishing problem? The non-excludability of a common property resource can lead to both overproduction and excessive entry. Essentially, the existing mechanisms restrict production through the regulation of the average catch per national fleet by means of national and sectoral quotas and/or control over mesh sizes. It may be equally necessary to adopt policies relating to entry through the management of fleet size and the use of decommissioning grants etc. These mechanisms are not alternatives, they are rather complementary means of 'solving' the common property problem. Controlling average catch levels without controlling entry will exacerbate the problem, as the market price of fish will rise in response to the restriction in supply. Recent history illustrates this: in 1986 the UK and other countries agreed to reduce fleet sizes by $3 \%$ by 1991 . Instead there has been an increase by $20 \%$, leading to a current estimated overcapacity of $40 \%$. The period has been characterised by smaller catches from more vessels offset by higher prices (haddock increased in price by $42 \%$ from 1989 to 1990 ).

Finally, there are potentially important lessons to be learned from this case study for environmental policy generally, when cross-national cooperation is required to regulate the exploitation of common property resources. Such cooperation will exist only at the rhetorical level unless due consideration is given to the informational requirements for effective monitoring and enforcement.

10 Obviously, the omission of land-based enforcement data is a limitation of the results. However, the approach taken here is justifiable to the extent that the objective of the excercise was to examine the cost-effectiveness of sea-based enforcement methods, independently of other enforcement methods. 
APPENDIX:

Mnemonics used in model estimation:

$\mathrm{C}$

$\mathrm{CCATCH}$

$\mathrm{HCATCH}$

CCATCHLn

HCATCHLn

CMASS

HMASS

CMASSL

HMASSL

RECRLn

DUMDEN-DUMUK

FEB-DEC

CODTAKE

HADTAKE

CODTAKEL

HADTAKEL

BOARDVES

ACTVES

VESSELS
$=$ constant

$=$ total nominal catch of cod reported to ICES

$=$ total nominal catch of haddock reported to ICES

$=$ total catch of cod lagged $n$ years

$=$ total catch of haddock lagged $\mathrm{n}$ years

$=$ total stock biomass of cod ('000 tonnes)

$=$ total stock biomass of haddock ('000 tonnes)

$=$ CMASS lagged one year

$=$ HMASS lagged one year

$=$ recruitment at age 0 ( 1 for cod $)$, lagged $n$ yaers

$=$ dummy variables for nationality

= dummy variables for month

$=$ reported monthly landings of $\operatorname{cod}(' 000$ tonnes liveweight) as proportion of national quota

$=$ reported monthly landings of haddock ('000 tonnes liveweight) as proportion of national quota

$=$ CODTAKE lagged one month

$=$ HADTAKE lagged one month

$=$ monthly number of boardings per vessel

$=$ monthly number of actions per vessel

$=$ monthly recorded number of vessels in UK zone

\section{REFERENCES}

BARTEL, A.P., and THOMAS, L.G. (1982), 'OSHA Enforcement, Industrial Compliance and Workplace Injuries' NBER Working Paper No 953.

CHAMBERLAIN, G. (1984), 'Panel Data' in Griliches and Intriligator, Handbook of Econometrics, Vol. 2 (North Holland).

CHOW, G.C. (1960), 'Tests of Equality Between Sets of Coefficients in Two Linear Regressions', Econometrica, 28, $591-605$.

COOKE, W.N. and GAUTSCHI, F.H. (1981) 'OSHA Plant Safety Programs and Injury Reduction' Industrial Relations, 245-257.

FENN, P. and VELJANOVSKI, C. (1987), 'A Positive Economic Theory of Regulatory Enforcement' Economic Journal, 98, 1055-1070.

FENN, P. (1987), 'Enforcement Policy and the Impact of Regulatory Controls on the Occupational Absorption of Lead', Report to the Health and Safety Executive (Centre for Socio-Legal Studies).

National Audit Office (1987), Financial Support for the Fishing Industry in Great Britain (HMSO, 1987).

VISCUSI, W. Kip (1979), 'The Impact of Occupational Safety and Health regulation', Bell Journal of Economics.

WHITE, H. (1980), 'Using Least Squares to Approximate Unknown Regression Functions', International Economic Review, 21.

WHITE, H. (1982), 'Maximum Likelihood Specification of Misspecified Models', Econometrica, 50, $1-26$. 